\title{
UHF-Band Wireless Power Transfer System for Structural Health Monitoring Sensor Network
}

\author{
Tansheng Li, ${ }^{1}$ Kikuzo Sawada, ${ }^{2}$ Harutoshi Ogai, ${ }^{1}$ and Wa Si ${ }^{1}$ \\ ${ }^{1}$ Graduate School of Information, Production and Systems, Waseda University, Kitakyushu 808-0135, Japan \\ ${ }^{2}$ Hibikino Department, Yoshikawa Kogyo Co., Ltd., Kitakyushu 808-0138, Japan \\ Correspondence should be addressed to Tansheng Li; anvaya@hotmail.co.jp
}

Received 6 April 2013; Revised 16 September 2013; Accepted 1 October 2013

Academic Editor: Chris Bowen

Copyright (C) 2013 Tansheng Li et al. This is an open access article distributed under the Creative Commons Attribution License, which permits unrestricted use, distribution, and reproduction in any medium, provided the original work is properly cited.

\begin{abstract}
For detecting and measuring health conditions of bridges, wireless sensor networks are used in these days. However, battery life is critically restricting the application and maintenance cost of sensor network systems. To extend life time, a wireless power transfer system at UHF band is introduced to supply the current wireless sensor network. This power transfer system is based on electric wave at $950 \mathrm{MHz}$. This power transfer system is redesigned for tiny power transmission, including a combination of a rectenna and a Cockcroft-Walton boost converter, battery board, and a control board. Also, current wireless sensor network is redesigned for power transfer system. The working flow of sensor network is modified to bottom-to-top to save power of sensor modules which are the power bottleneck of this sensor system. As a result, the system is able to support a sensor module continuously with received power of $-14 \mathrm{dBmW}$, when the transmitting antenna is $30 \mathrm{dBmW}$ at 10 meters distance.
\end{abstract}

\section{Introduction}

In Japan, most landforms are rugged by mountains and rivers. Therefore, bridges played a critical role in daily transports. However, the average age of bridges in Japan is over 20 years, and due to rapid nature disasters, bridge health monitoring techniques have become an important field.

Recently, in the field of bridge health monitoring, wired sensor networks and wireless sensor networks are both used. However, a wired sensor network system usually costs much more than a wireless one. In a previous research on Donghai Bridge, optical fiber and GPS servers are implied to transmit data [1]. Although it is the optimal method to monitor one of the longest bridges in the world, price of this system is unacceptable for most of bridges in Japan, because each module costs over 10,000 USD. To monitor and detect the bridges' health condition, several health-monitoring systems (Figure 1) based on wireless sensor networks are developed worldwide including our original system [2]. In this sketch, S stands for sensor, R stands for router, and C stands for data collection device.

In this system, sensors are used to acquire bridge vibration. After measurement, sensor modules transfer their data to the data collection device via routers. The data collection device is able to transfer data to a computer via USB cable or to the Internet via a network module.

However, a problem still occurred in this system. Under a current measurement plan, the sensor network activates for 15 seconds per day to measure bridge vibration, and battery is able to supply this system for 10 years. Also, due to the leakage of battery, increasing battery capacity will not extend system life as expected.

Since battery exchange for bridge monitoring system costs many resources, it is expected to find a way for unlimited power. To solve this problem and extend the battery life, some methods are raised such as solar energy or wind energy. However, since the sensors are attached beneath the deck or on the piers, solar panels would not be able to receive enough sunshine for the system. Also, wind power generators will suffer from the moist environment under the bridge, and the maintenance of wind energy generator is technically similar to changing batteries. Therefore, to provide energy generation with a nearly infinite life, or at least the same as a bridge's life, wireless energy transfer is brought to this system, with expected transmission distance over 10 meters. 


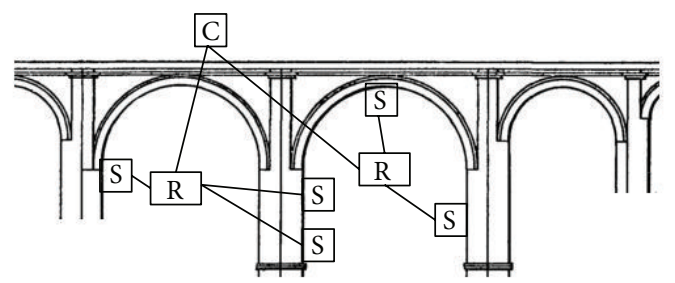

FIGURE 1: Basic sketch of wireless sensor network bridge health monitoring system.

Different from other wireless power transfer systems, aiming at large power transfer, this system focuses tiny power transfer under $10 \mathrm{~mW}$. One of the reasons is that, depending on radio law in Japan, output of an antenna at $950 \mathrm{MHz}$ is limited up to $1 \mathrm{~W}$. Therefore, at the receiving side, power decreases to less than $1 \mathrm{~mW}$, considering the antenna gain and the free-space attenuation. On the other hand, electric radiation at $1 \mathrm{~W}$ level has not been proved safe for human health yet. Therefore, this research chose tiny power transfer for recharging wireless sensor modules.

In this research, we mainly focused on the receiving side, including the rectenna and boost converter, a low-power controlling board, and modification of the current wireless sensor module. The architecture of this system is shown in Figure 2.

\section{System Design}

2.1. Rectenna and Boost Converter. A rectenna is an antenna with rectifying circuit, which is used to convert microwaves to DC power [3]. In this system, for the demand of power gain and size, we chose microstrip antenna as receiving antenna [4].

For traditional microstrip antenna, size is the first priority. However, in this wireless power transfer system, the antenna gain and efficiency have more priority than size. To increase the antenna gain, a stacked architecture design is applied to increase the receiving bandwidth and the antenna gain [5]. The antenna is shown in Figure 3.

Moreover, the rectifying circuit uses a low pass filter (LPF) to prevent reradiation of harmonic effect and a quarterwavelength transmission line for impedance matching [6]. In previous researches, quarter-wavelength transmission line cannot be applied in the rectifying circuit, because the antenna's size cannot fit the length of quarter wavelength for $950 \mathrm{MHz}$. However, since size is not the first priority in this research, quarter wavelength transmission line is implied, which is shown in the right figure in Figure 3.

Evaluation result of the antenna is shown in Figure 4. In this evaluation, the power of transmitting antenna and receiving antenna is fixed with $10 \mathrm{~m}$ distance; hence, we can measure relation of the two antennas. By adjusting the output of the transmitting antenna ( $x$-axis of Figure 4$)$, the power (voltage) output of the receiving antenna ( $y$-axis of Figure 4) is measured. Power transmitting frequency is set to $950 \mathrm{MHz}$, and loaded resistance is $20 \mathrm{KOhm}$. In this experiment, transmitting side uses a Speedway Revolution UHF RFID Reader manufactured by Impinj with a linearlypolarized antenna YAP-100LP manufactured by Yeon.

As a result from the experiment, the rectenna circuit is able to provide $52 \mu \mathrm{W}$ power at $10 \mathrm{~m}$ distance, which is equal to $-12.84 \mathrm{dBm}$. Since the output voltage is only about $1 \mathrm{~V}$, voltage must be boosted to recharge battery working at $4 \mathrm{~V}$. In this research, different types of boost converters are tested. Traditional method for large power transfer is a transformer with IC chips. However, this type of boost converter consumes over $60 \mu \mathrm{W}$, which is larger than the antenna's output. Considering power consumption and operating voltage, a 3level Cockcroft circuit with low-power oscillation circuit is designed $[7,8]$. The sketch of boost converter is shown in Figure 5 [9].

The combination of rectenna and boost converter is evaluated by actual wireless power transfer antenna. The experiment's result of output voltage and current is shown in Figure 6. In this experiment, three resistances are loaded on the end of the boost converter separately. Result of the experiment shows that at $10 \mathrm{~m}$ distance, output voltage is over $4 \mathrm{~V}$, which means that the boost converter is able to recharge batteries. Moreover, current consumption of this boost converter is less than $10 \mu \mathrm{A}$, while input voltage is $0.7-0.8 \mathrm{~V}$. As a result, power consumption of this boost converter is about $5 \mu \mathrm{W}$.

Therefore, the output power after the boost converter became $47 \mu \mathrm{W}$. This tiny power will be charged into secondary batteries and support a sensor module and a controlling board.

2.2. Battery System and Control Board. For wireless power transfer system, it is required for frequently charging and discharging. In this system, we choose micro energy cells made by THINERGY. The MEC101 energy cell works at $4.1 \mathrm{~V}$, with $1.0 \mathrm{mAh}$ and $40 \mathrm{~mA}$. The size of this energy cell is $25.4 \mathrm{~mm} \times 25.4 \mathrm{~mm} \times 0.17 \mathrm{~mm}$ [10]. However, since the manufacturer is warning that discharging the energy cell below a specified discharge cutoff line (about $2.1 \mathrm{~V}$ ) would cause permanent damage to the energy cells, we made a protection circuit (a.k.a. control board, the yellow board in Figure 7) within the energy-cell circuit system. Moreover, another function of the control board is to detect high battery for pretending the system of overdischarging. Also, to coordinate with all of the systems, we designed the working procedure and realized it with the control board.

For an automatic controlling system, we used R8c/27 microcontroller produced by Renesas to control this whole system.

Obviously, the control board is also fully powered by the secondary battery unit, which means that it is $100 \%$ powered wirelessly. Hence, power consumption of this control board became the first priority. Another reason to use this microchip-based control board is that the sensor module costs over $50 \mu \mathrm{W}$ even in sleep mode because of complicated circuit. A microcontroller board costs much less power than a sensor module, and it is able to shut down the sensor module in most time of a day, except the 15 seconds measurement.

Depending on actual experiment, the transfer system can transfer about $47 \mu \mathrm{W}$ s power at 10 meters distance measured 


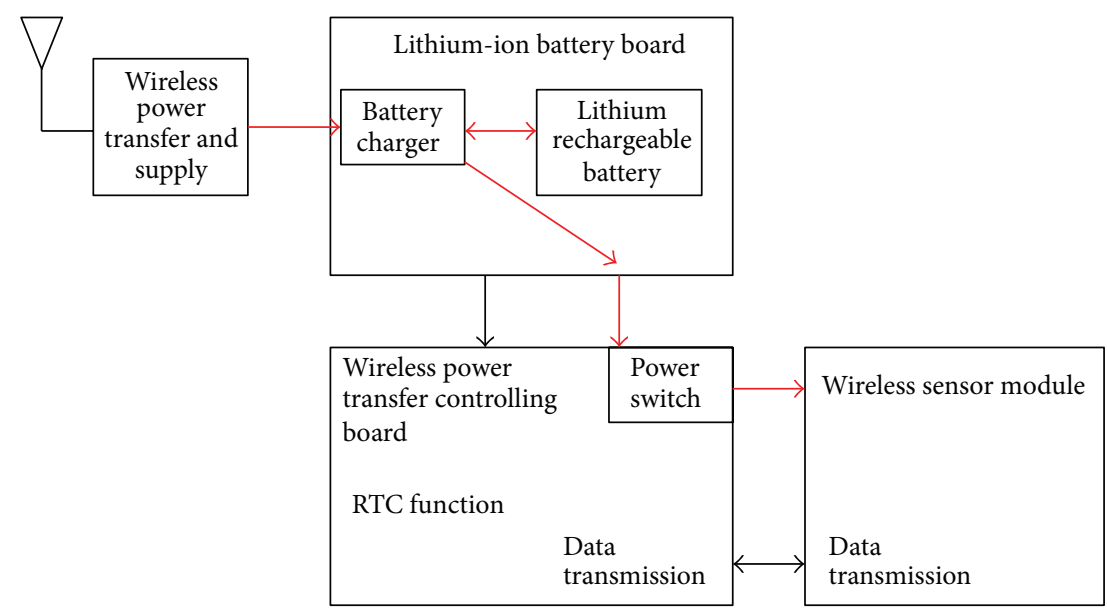

$\longrightarrow$ Power flow

$\longrightarrow$ Data transmission flow

FIgURE 2: Architecture of the wireless power transfer system.
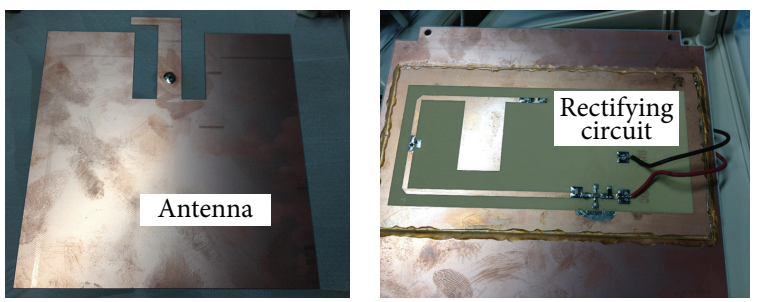

FIGURE 3: The receiving antenna with rectifying circuit.

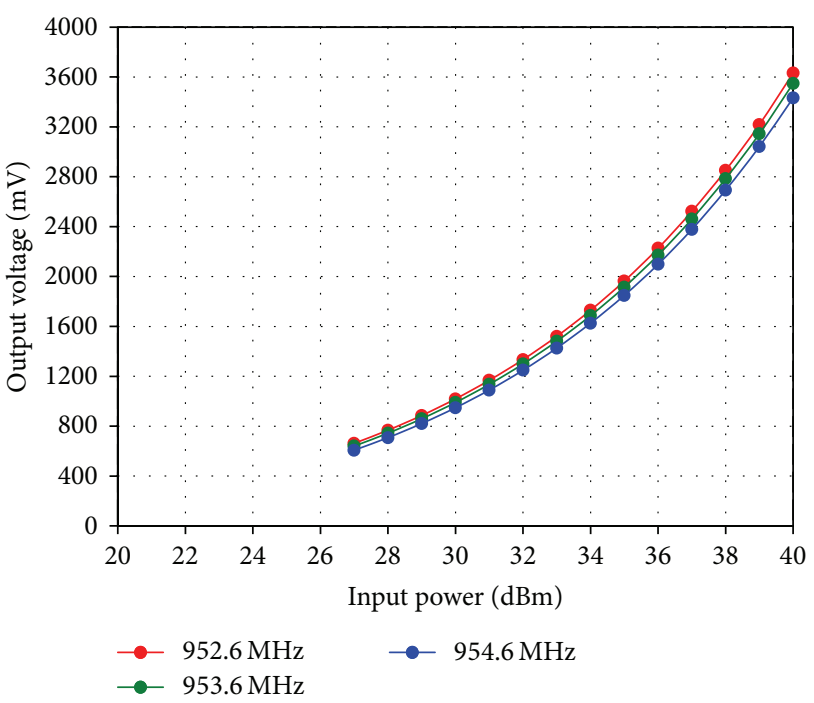

FIGURE 4: Performance evaluation of the receiving antenna.

at the end of the boost converter. It means that if the microcontroller board works at more than $47 \mu \mathrm{W}$, the whole system became meaningless. However, the chip we used costs $150 \mu \mathrm{W}$ on low-speed clock mode, even $115 \mu \mathrm{W}$ in wait
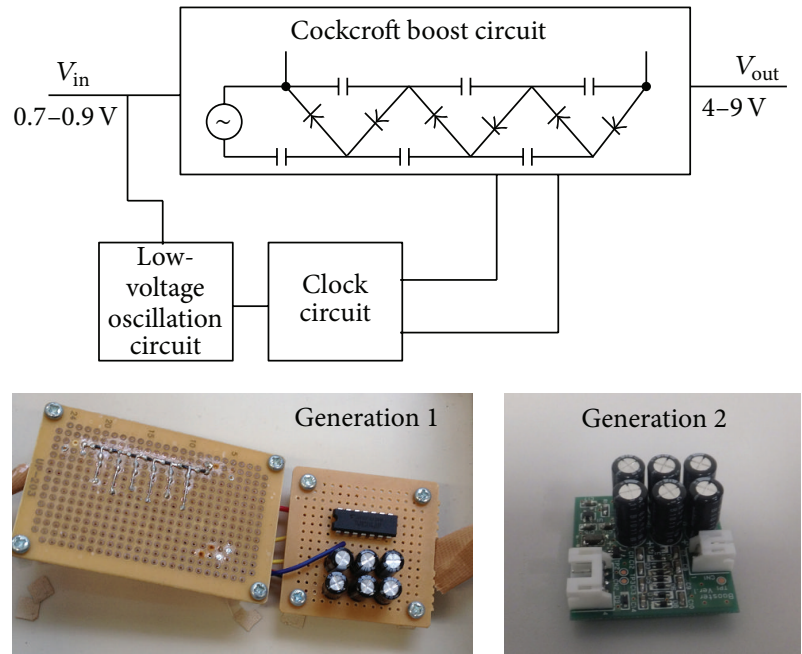

FIgURE 5: Design and implement of boost converter.

mode while low-speed on-chip oscillator is on. To solve this problem, the following methods are done.

Firstly, switch the microchip into wait mode. In oscillator mode or outer clock mode, power consumption of the microchip is not less than $650 \mu \mathrm{W}$. Even in wait mode, the microcontroller will also cost $125 \mu \mathrm{W}$ while on-chip oscillator is still on. Therefore, we switched all on-chip oscillators, with XIN clock stopped. Also, an outer oscillator is added as the input XCIN clock with low driving ability. In this case, the power consumption of the microchip is about $10 \mu \mathrm{W}$.

Moreover, to keep waiting mode as long as possible, interrupt of the microchip is also modified for the longest time interval. In this case, it is set to $63.5 \mathrm{~s}$.

At last, after other procedures of switching off other functions in the micro-chip and controlling board, average power consumption of the controlling board is decreased to $11 \mu \mathrm{W}$. 


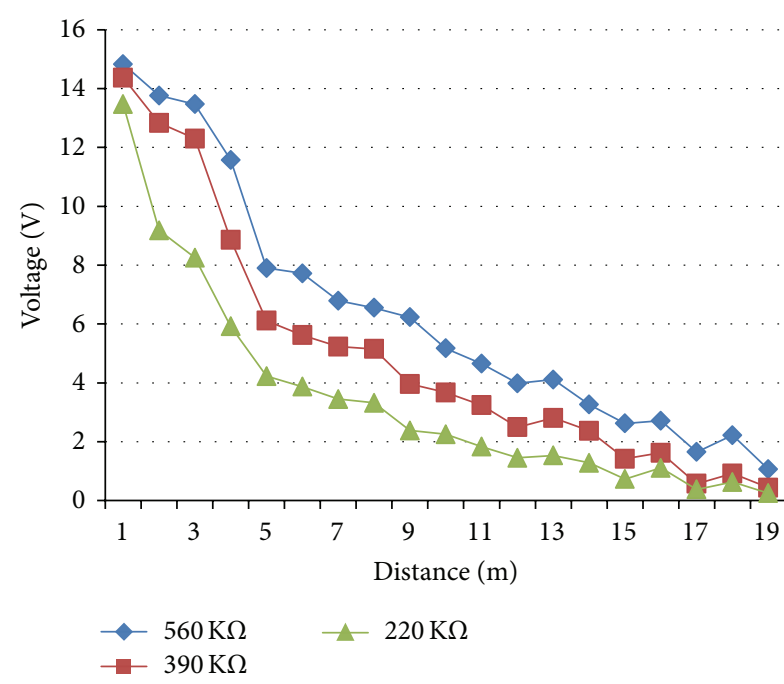

(a)

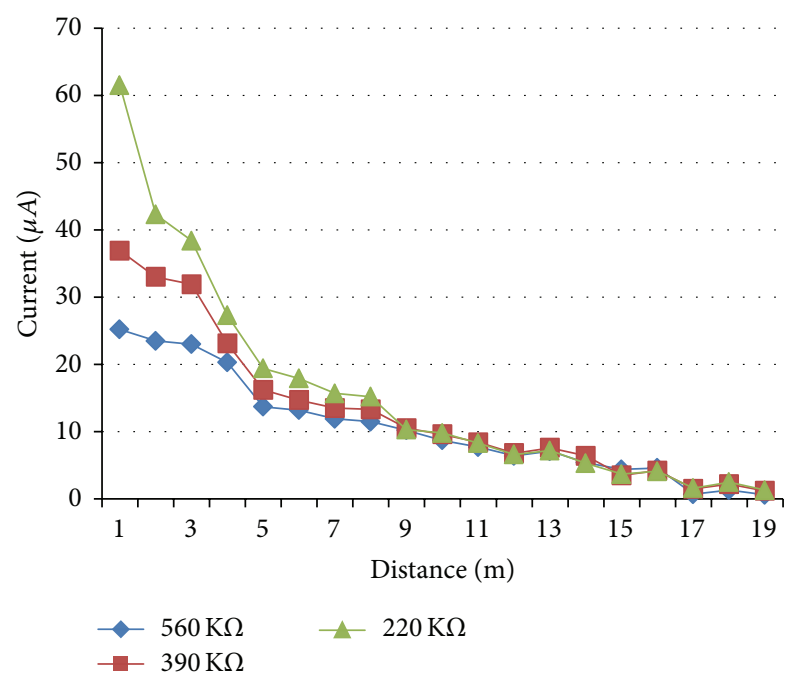

(b)

FIGURE 6: Evaluation of the boost converter.

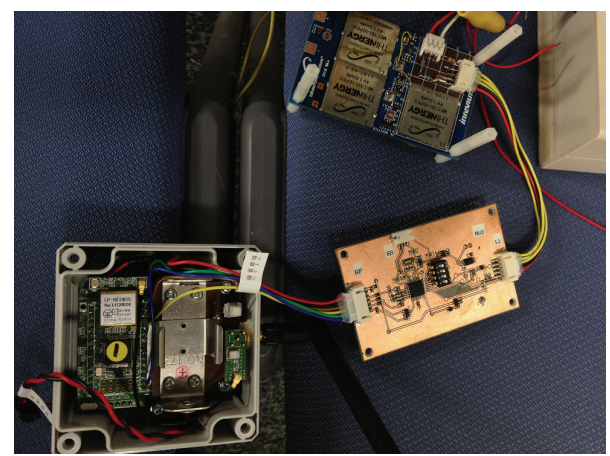

Figure 7: Photo of battery system, control board, and a sensor module. The upper board is the battery system and the right-bottom board is the control unit.

Photo of battery system, controlling board, and a sensor module is shown in Figure 7.

The total capacity of the battery unit is $3 \mathrm{mAh}$ working at $4 \mathrm{~V}$. Therefore, the total energy is $12,000 \mu \mathrm{Wh}$. Since the output of rectenna is $47 \mu \mathrm{W}$ and controlling board consumes $11 \mu \mathrm{W}$, final rechargeable power into the controlling board per day became $864 \mu \mathrm{W}$. Also, a sensor module costs $688 \mu \mathrm{W}$ per day, therefore, ensuring 15 seconds measurement every day. The wireless power transfer system is able to support a sensor module, with $178 \mu \mathrm{Wh}$ (about 1/60 of the battery unit) surplus per day.

2.3. Modification of the Current Wireless Sensor Network. Figure 8 shows the working procedure of the previous sensor network and current wireless sensor network.

In Figure 8, comparing these two figures, it is shown that in the previous system, the procedure is from top to bottom, which means the collector controls the whole network. Since the wireless sensor modules are always waiting for commands from upper layer, it is switched to sleep mode at almost time.
However, for a sensor module, it is going to cost much power to wait for the start measurement signal. In current system, sensor module itself controls the system. In this way, it is possible for us to shut down the sensor modules and activate them using the microchip-based board, with much less power consumption.

While processing the collected data, the previous system will save all the collected data into its own buffer and transmit it to the collector after the whole measuring is finished. In this system, since the data is transmitted one by another, all the sensor modules will cost more time (10 seconds by each module, 3 seconds by each axis) and power for waiting in the transmission queue. In the current system, data is transmitted during measuring, which means after measuring, transmission will be terminated immediately, in order to save power. Therefore, in a system with 3 sensor modules, sensor module's average activation time is 35 seconds in previous system, while current system requires only 15 seconds.

\section{Experiments}

Since some experiments of the rectenna and the boost converter are introduced in Section 2, experiment of validity for the whole system is going to be introduced in this chapter.

Firstly, we tested the discharging curve of the battery system, using our sensor modules. Result shows that the discharging curve is basically a straight line. And after $150 \mathrm{~s}$ of discharging, the voltage of the battery system will fall to $3.9 \mathrm{~V}$ from $4.1 \mathrm{~V}$.

Moreover, several experiments are carried out for testing this system. Firstly, output performances in different environments of this system are tested. Test result is shown in Figure 9.

To reduce the effect of electrical wave reflection, first experiment is done on a building roof, with no higher buildings around $100 \mathrm{~m}$. Experiment result is shown in Figure 9(a). From this figure, it is shown that even at the distance of 


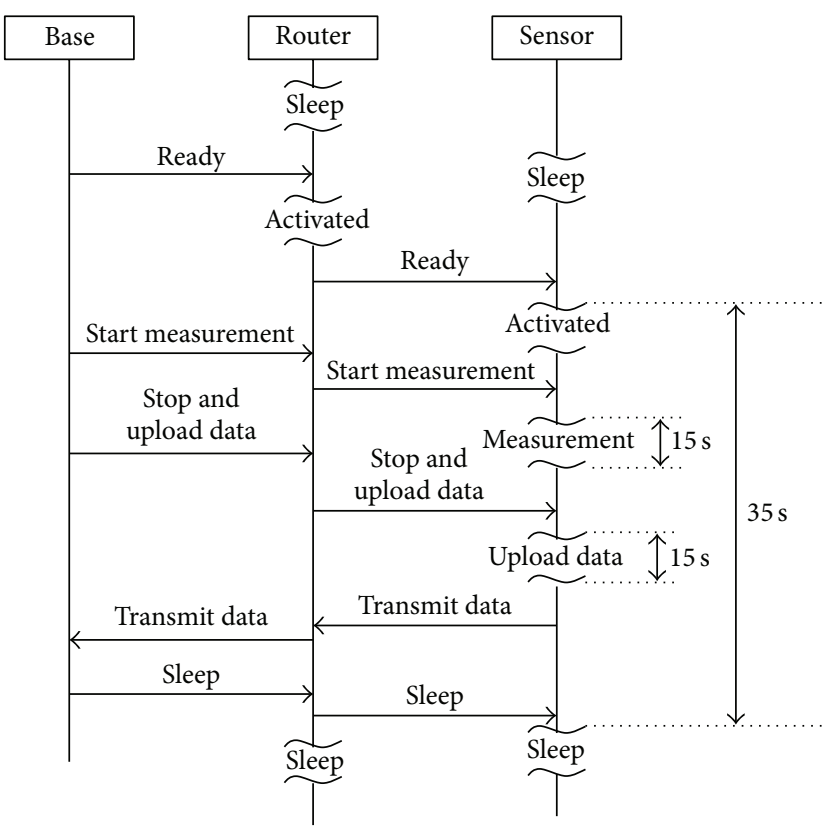

(a)

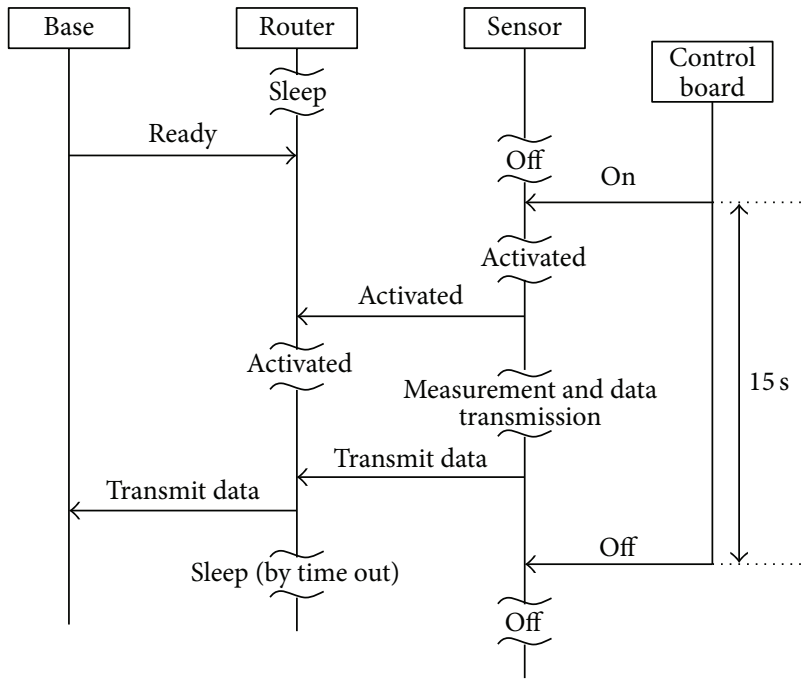

(b)

FIGURE 8: Working procedure of previous sensor system and current sensor system. (a) Previous system with top-to-bottom flow, (b) current system with bottom-to-top flow.

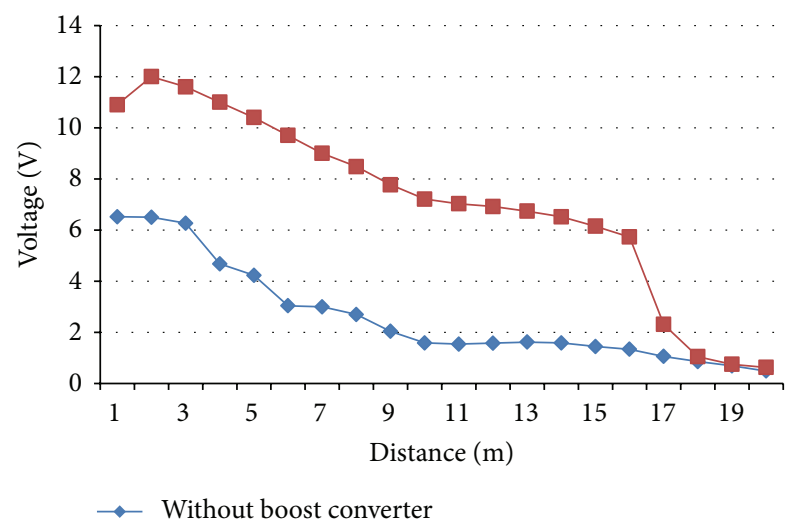

(a)

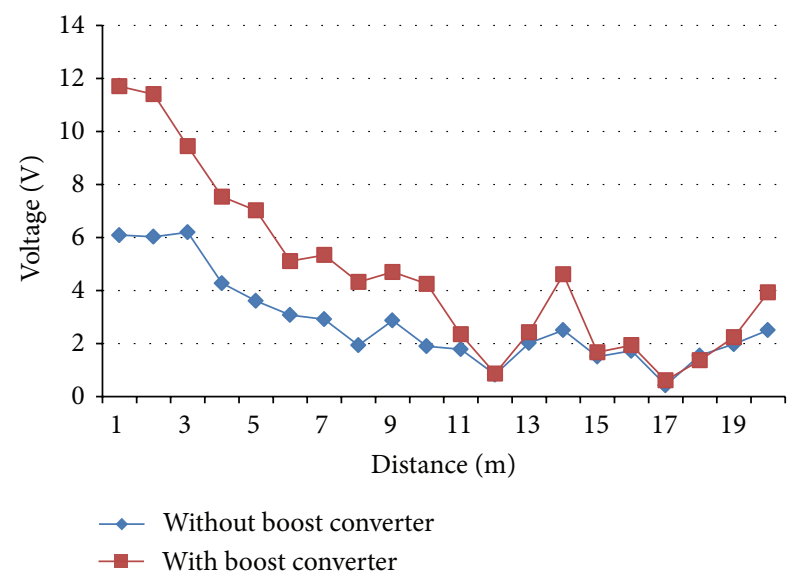

(b)

FIGURE 9: Output performance of the wireless power transfer.

16 meter, the voltage is still boosted to about $6 \mathrm{~V}$ by the boost converter. In other words, at the distance of 16 meter, the wireless power transfer system is still possible to charge batteries.

In real application, bridges are made of steel or reinforced concrete, which strongly prevent UHF microwave. For confirmation, we did another experiment, while there are iron fence and reinforced concrete, which locates less than $2 \mathrm{~m}$ from the antenna. The wireless transmission result is shown in Figure 9(b).

The result shows that when sending and receiving antennas are set in-sight, power transfer will be influenced but not obviously, even if we attached both antennas on the iron fence. However, the power transfer is falling suddenly due to the reflection of the concrete, but the boost converter is still able to boost voltage at about $10 \mathrm{~m}$ distance in concrete environment.

During the discharging experiment, the following facts are known. First, while the secondary battery is fully charged, the voltage will be $4.1 \mathrm{~V}$. Second, while overdischarging, permanent damage will be done to the battery system. Therefore, one battery unit is able to drive a sensor module for about 150 seconds. Third, after $150 \mathrm{~s}$ of discharging, the voltage of the battery system will fall to $3.9 \mathrm{~V}$ from $4.1 \mathrm{~V}$. Fourth, the discharging curve can be treated as a straight line.

From these four facts, two conclusions can be inferred. Conclusion 1: for the battery, voltage changing of $0.01 \mathrm{~V}$ 


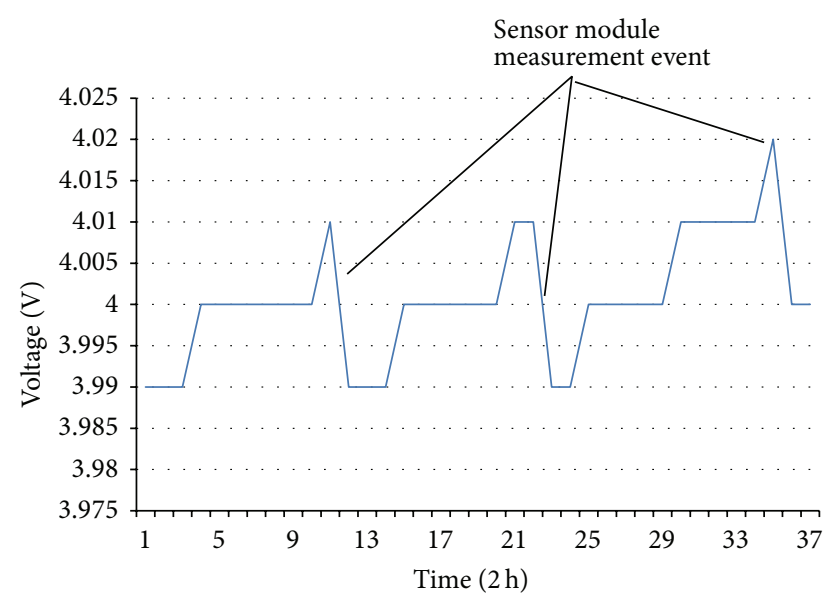

FIGURE 10: Result of a 72-hour wireless power transfer experiment.

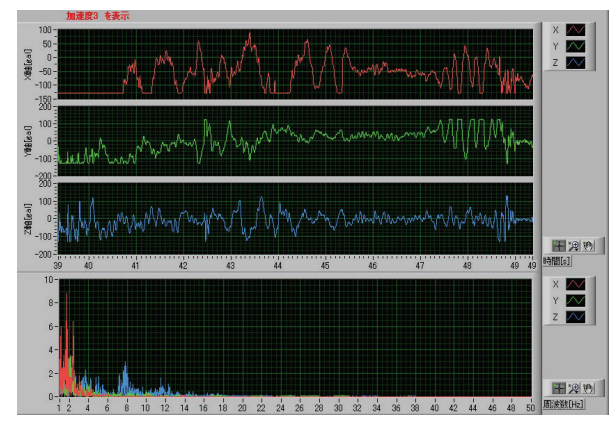

FIGURE 11: The 3-axis acceleration data of $10 \mathrm{~s}$ measured by a sensor module, with spectrum analysis result.

equals 5\% capacity. Conclusion 2: 15 s of measurement equals $10 \%$ battery capacity.

Depending on these two conclusions, we did another 72 hours experiment to verify this system. The basic point is whether this system can run continuously and periodically. Theoretically, this system can be driven only by wireless transferred power.

In the next experiment, we cleaned a room and then adjusted distance between the sending and receiving antennas to simulate the power transfer strength over $10 \mathrm{~m}$ distance. After setting up devices, we measured the voltage of the battery system every 2 hours for 3 days. The experiment result is shown in Figure 10. From this figure, it is shown that the voltage of the battery system is changing up slowly. At the times of 11,23, and 35, there is a quick drop of voltage, which represents for sensor module measurements. After three days, the voltage, right after sensor measurement, increases from $3.99 \mathrm{~V}$ to $4.00 \mathrm{~V}$. It stands for that after working 3 days, system battery changes for $5 \%$ (depending on conclusion 1), which satisfies our calculation in Section 2.2.

Additionally, 3-axis acceleration data measured by sensor modules is shown in Figure 11.

\section{Conclusions and Future Works}

In this paper, we have realized a wireless power transfer system at $950 \mathrm{MHz}$ using a secondary battery power unit for wireless sensor network.

For realizing this system, a rectenna-boost converterbattery system is proposed to drive sensor modules with working voltage at $3.3 \mathrm{~V}$. The output of the antenna is about $-8 \mathrm{dBm}$. Although there is a boost converter after the rectenna, the combination of the rectenna and boost converter is able to provide power of $47 \mu \mathrm{W}(-13.2 \mathrm{dBm})$, which has more efficiency than previous system [11] without boost converter. Comparing with previous system [11] in the same condition (distance between the two antennas is $10 \mathrm{~m}$, and output of the sending antenna is $1 \mathrm{~W}$ ), although there is a boost converter after the rectenna, the combination of the rectenna and boost converter is able to provide power of $47 \mu \mathrm{W}(-13.2 \mathrm{dBm})$, which has more efficiency. While the power consumption of controlling unit is $11 \mu \mathrm{W}$, power of $36 \mu \mathrm{W}$ is still available for recharging the battery system, which is proved to be able to work $15 \mathrm{~s}$ per day for daily measurements of bridge health or other structures.

There is still some problem to be solved. First, generally bridges are made of steel or concrete, whose materials prevent UHF electromagnetic wave. To solve this problem, we can set the power sending antenna and power receiving rectenna to in-sight areas. Depending on our experiments, while antennas are put in-sight, power attenuation is not obvious.

However, this solution brings another problem. This system is proved to be effective at $10 \mathrm{~m}$ distance. While setting antennas, distance between two antennas will be over 10 meters. To expand energy transmission range and efficiency, several methods such as increasing sending power and modifying sending antenna are considered. During an academic exchange between our lab and mechanical engineering laboratories of India Institute of Technology Kanpur, a method of flexible antenna is discussed. In that research, antenna is made of flexible materials and is able to change its shape to enhance transmission directivities.

For future work, it is necessary to extend power transfer distance and reduce power consumption of sensor modules. However, radio law in Japan will change in one or two years. After the modification of radio law, power transfer frequency will be changed from $950 \mathrm{MHz}$ to $920 \mathrm{MHz}$. Receiving antenna will be adjusted at that time.

\section{References}

[1] Y. Wang and W. Gao, "A GPS Bridge 3D-Monitoring System, Implement on Donghai Bridge," pages 1-11, 2008.

[2] T. Li, H. Ogai, H. Xiao, and N. Yamauchi, "A multi-hop wireless sensor system for bridge health monitoring," IEEJ Transactions on Electronics, Information and Systems, vol. 131, no. 10, pp. 1760-1766, 2011.

[3] N. Shinohara, M. Furukawa, Y. Nakai, and H. Matsumoto, "Development of rectenna for high power microwave energy transmission," IEICE B-II, pp. 346-348, 1996 (Japanese), J79-BII.

[4] Y. C. Noh, C. Cha, J. Park, J. C. Choi, and M. Kim, "Optimized wireless power transmission circuit for energy transfer," in 
Proceedings of the 31st International Telecommunications Energy Conference (INTELEC '09), pp. 1-3, October 2009.

[5] S. Egashira and E. Nishiyama, "Stacked microstrip antenna with wide bandwidth and high gain," IEEE Transactions on Antennas and Propagation, vol. 44, no. 11, pp. 1533-1534, 1996.

[6] N. Shinohara, H. Matsumoto, A. Yamamoto et al., "Development of high efficiency rectenna at mW input," Technical Report SPS2004-08 (2005-01), Institude of Electronics, Information and Communication Engineers, Tokyo, Japan, 2005.

[7] Y. Watanabe, K. Watanabe, and H. Igarashi, "Optimization of meander line antenna considering coupling between nonlinear circuit and electromagnetic waves for UHF-band RFID," IEEE Transactions on Magnetics, vol. 47, no. 5, pp. 1506-1509, 2011.

[8] J. Curty, N. Joehl, C. Dehollain, and M. J. Declercq, "Remotely powered addressable UHF RFID integrated system," IEEE Journal of Solid-State Circuits, vol. 40, no. 11, pp. 2193-2202, 2005.

[9] J. F. Dickson, "On-chip high-voltage generation in MNOS integrated circuits using an improved voltage multiplier technique," IEEE Journal of Solid-State Circuits, vol. 11, no. 3, pp. 374-378, 1976.

[10] “THINERGY official website," http://www.infinitepowersolutions.com/images/pdfs/THINERGY_MEC101_DataSheet_v34_DS1001.pdf.

[11] T. Umeda, H. Yoshida, S. Sekine, Y. Fujita, T. Suzuki, and S. Otaka, "A 950-MHz rectifier circuit for sensor network tags with 10-m distance," IEEE Journal of Solid-State Circuits, vol. 41, no. 1, pp. 35-41, 2006. 

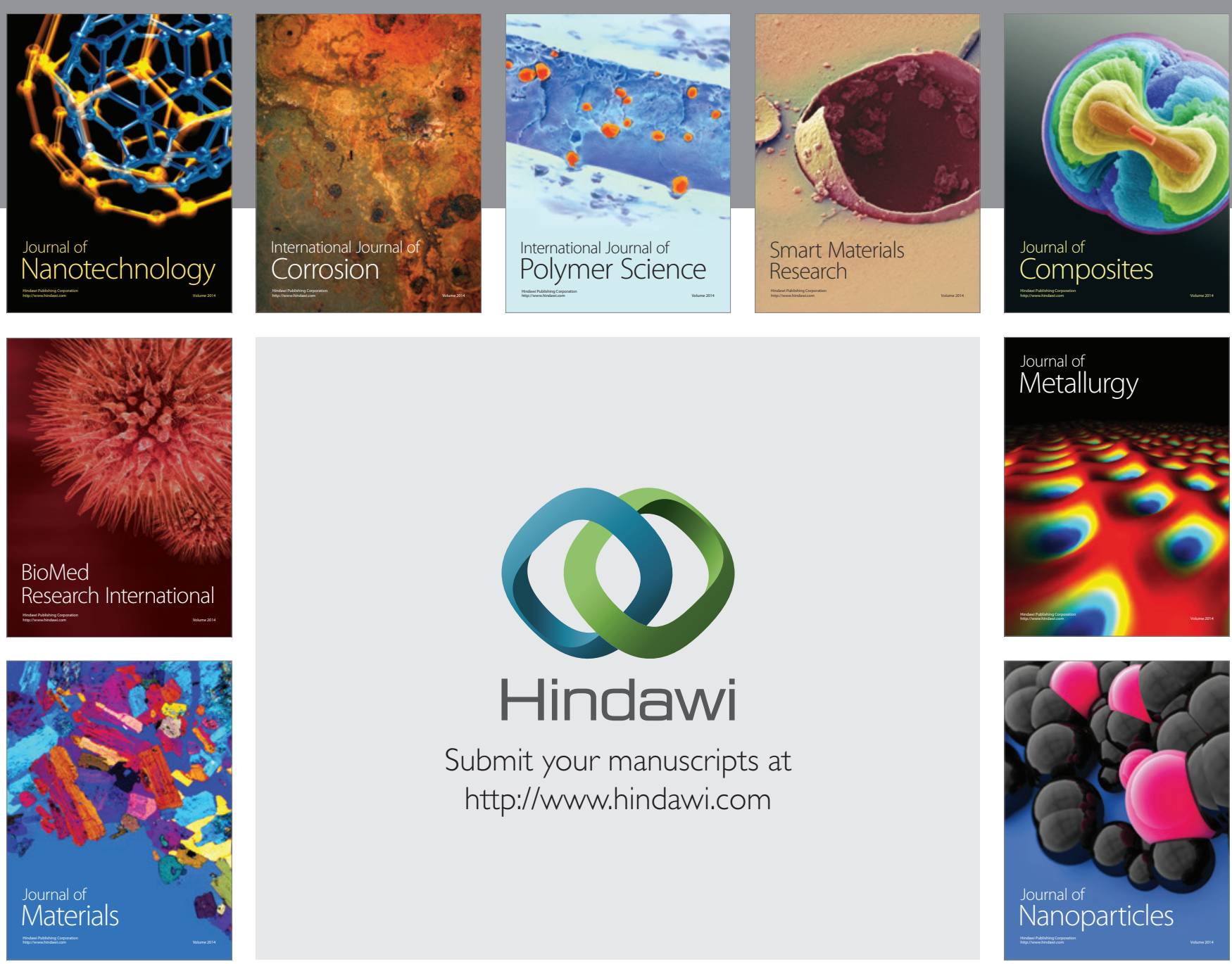

Submit your manuscripts at http://www.hindawi.com
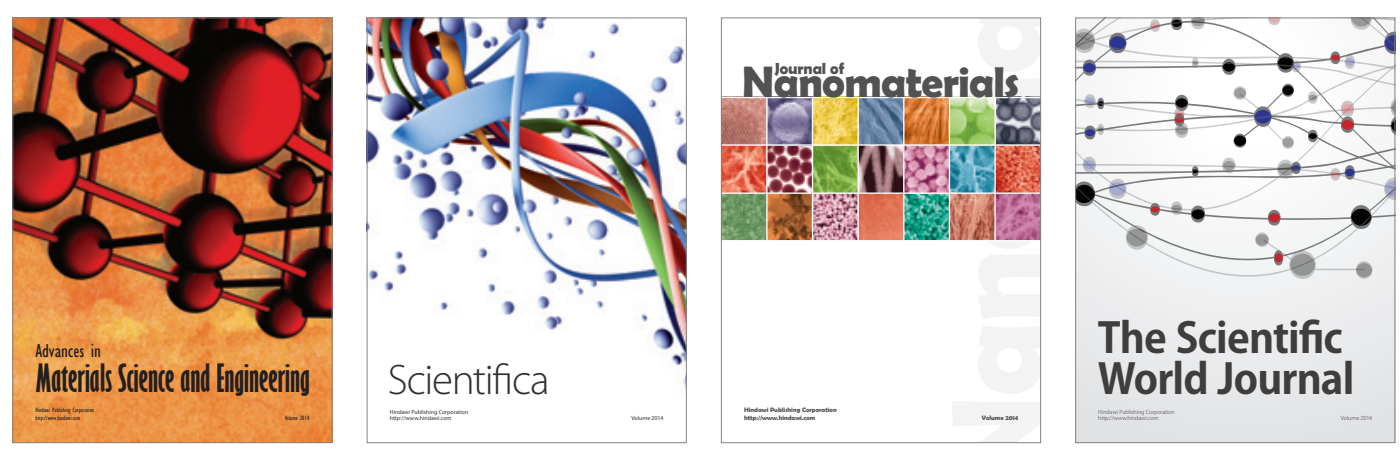

\section{The Scientific World Journal}
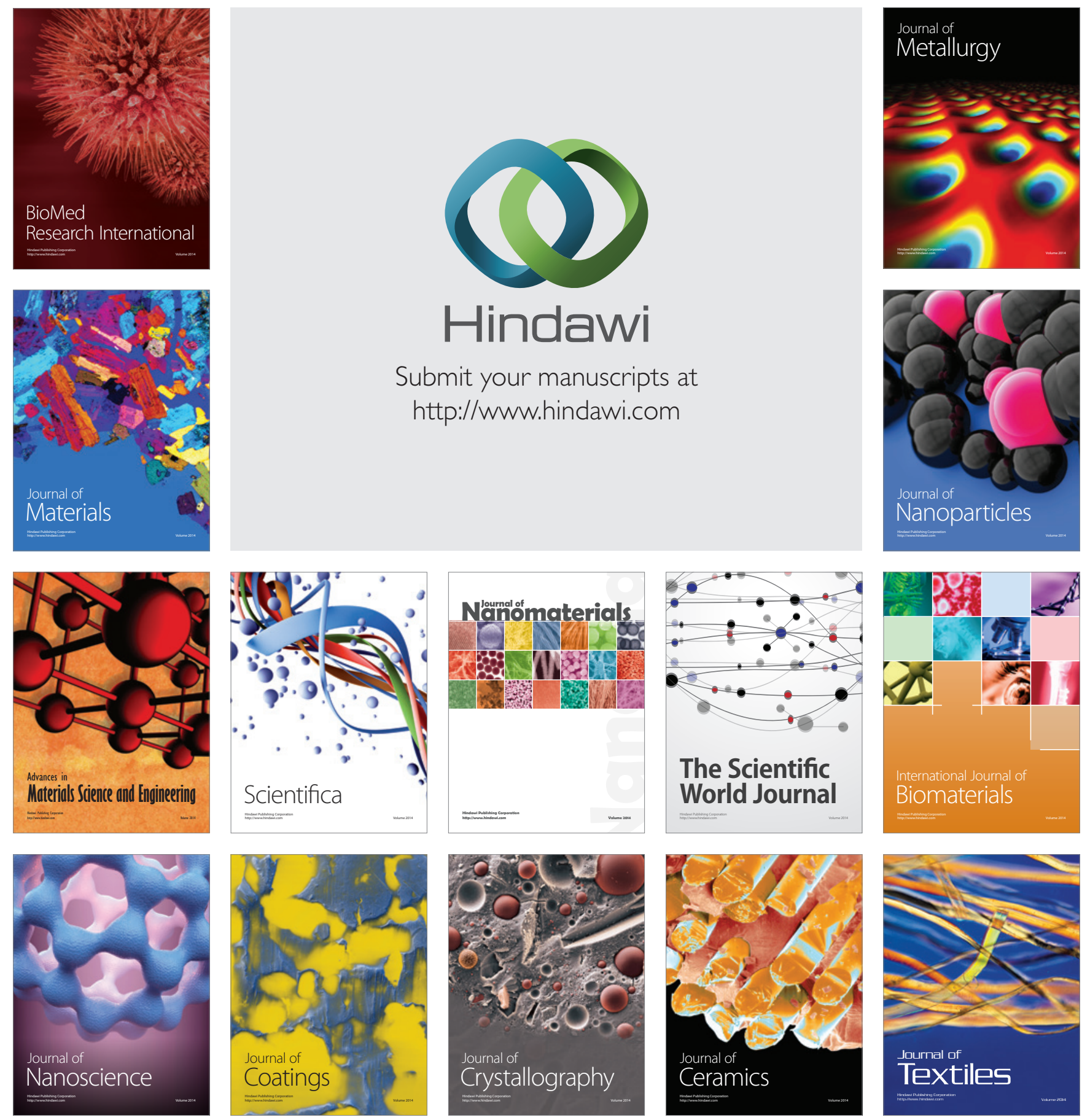